Brit. J. vener. Dis. (1964), 40, 109.

\title{
CHARCOT JOINTS
}

BY

\section{GEOFFREY STOREY}

Consultant in Physical Medicine, Hackney Hospital, London, E.9

Since the description given by Charcot (1868) there has been much discussion on the causation of this condition. On the one hand it has been widely agreed that purely mechanical factors can produce the features of Charcot joints. Eloesser (1917), from experiments with cats, concluded that trauma in a limb rendered anaesthetic by division of sensory nerves could lead to all the grotesque lesions seen in the Charcot joint, and the importance of trauma has been emphasized by many writers (Wile and Butler, 1930).

Other contributory factors which have been described are ataxia, with resultant mis-use of the joint, and atonia of muscles and ligaments allowing increased instability of the joint (Soto-Hall and Haldeman, 1940). The alternative view that some more active process is involved has not received support. Wyburn-Mason (1950) suggested that trophic nerves were of importance but this view has not been accepted because of the failure to demonstrate such nerves. Vasomotor effects, however, may be important as suggested by Watson-Jones (1952).

The possibility that some form of infection is involved is not considered likely (Kernwein and Lyon, 1942). At one time a luetic infection was incriminated but since it has been recognized that similar lesions occur in many other conditions this idea has been abandoned. Vishoot (1956) lists the various conditions which may result in Charcot joints.

It is well recognized that the Charcot joint runs a very variable course; the onset may be acute or insidious, and it may remain asymtomatic for many years. To investigate some of these problems, a series of 52 cases was studied. Radiographs and case histories were available for all of them so that the course of the disease could be followed both clinically and radiologically.

\footnotetext{
* Paper read to M.S.S.V.D. on January 25, 1963.
}

\section{Material}

The series comprised 52 patients ( 28 male and 24 female). The diagnoses are shown in Table I, and the involvement of various joints in Table II.

TABLE I

DIAGNOSIS IN 52 CASES

\begin{tabular}{|c|c|c|c|c|}
\hline \multicolumn{4}{|c|}{ Diagnosis } & \multirow{2}{*}{$\frac{\text { No. of Cases }}{37}$} \\
\hline Tabes Dorsalis . & $\cdots$ & $\cdots$ & $\cdots$ & \\
\hline Syringomyelia & $\cdots$ & $\cdots$ & $\cdots$ & 10 \\
\hline Diabetes Mellitus & $\cdots$ & $\ldots$ & $\cdots$ & 4 \\
\hline Injury to Sciatic & e. . & $\cdots$ & $\cdots$ & 1 \\
\hline Total .. & $\ldots$ & $\ldots$ & $\ldots$ & 52 \\
\hline
\end{tabular}

TABLE II

JOINTS AFFECTED

\begin{tabular}{|c|c|c|c|c|c|c|}
\hline \multicolumn{6}{|c|}{ Joints Affected } & \multirow{2}{*}{$\frac{\text { No. of Cases }}{30}$} \\
\hline Knees & . & $\cdots$ & $\cdots$ & $\cdots$ & $\cdots$ & \\
\hline Spine & . & $\cdots$ & $\ldots$ & $\ldots$ & $\ldots$ & 11 \\
\hline \multicolumn{4}{|c|}{ Feet (tarsus and phalanges) } & $\cdots$ & $\cdots$ & 10 \\
\hline Hips & $\cdots$ & $\cdots$ & $\cdots$ & $\ldots$ & $\cdots$ & 9 \\
\hline \multicolumn{5}{|c|}{ Hands (carpus and phalanges) } & $\ldots$ & 7 \\
\hline \multicolumn{2}{|c|}{ Shoulders } & $\cdots$ & $\cdots$ & $\cdots$ & $\cdots$ & 7 \\
\hline Ankles & $\cdots$ & . & $\cdots$ & $\ldots$ & $\ldots$ & 6 \\
\hline Elbows & $\ldots$ & $\ldots$ & $\ldots$ & $\ldots$ & $\ldots$ & 4 \\
\hline Wrists & $\ldots$ & $\ldots$ & $\ldots$ & $\ldots$ & $\ldots$ & 1 \\
\hline
\end{tabular}

In 27 cases there was involvement of only one joint, and in the rest the condition was polyarthritic.

Diabetes Mellitus.-The number of cases in this series was small (4 cases) so that few conclusions can be drawn from them. This may be attributed to the fact that the changes (found most frequently in the foot) have not always in the past been regarded as 
neuropathic in origin-infection and ischaemia having usually been incriminated. Different writers have differed in the emphasis placed on these three factors: Antes (1954) quoted a case with marked neuropathy without infection or vascular change; Parsons and Norton (1951) reported one in which peripheral vascular changes were marked and which improved after sympathectomy; Copland (1954) believed that infection was the main factor.

No doubt all three factors are present in many cases (Martin, 1954; Bailey and Root, 1947). If the changes seen in diabetes mellitus are accepted as a type of Charcot joint, it seems likely (as is claimed) that diabetes mellitus is now the second most common cause of the condition after tabes dorsalis.

Fig. 1 shows one case in this series, a man aged 74, where rapid bone destruction occurred in relation to a perforating ulcer but was reversed with reformation of the phalanx when the ulcer healed. In leprosy, where similar factors may be involved, Paterson (1955) believed the lesions to be usually related to infection.
Peripheral Nerve Lesions.-Only one such case occurred in this series. A man now aged 76 sustained a sciatic nerve lesion in the 1914-18 war; there were marked sensory changes with infection. The features (Fig. 2, opposite) are similar to those in the diabetic cases.

Syringomyelia and Tabes Dorsalis. - These may be considered together. Syringomyelia usually affects the upper limb (there was only one case of lower limb involvement in this series) and the changes are often atrophic in type (Fig. 3, opposite); in tabes dorsalis the lower limb is usually affected (in only five of 37 cases was the upper limb involved).

\section{History}

The onset was of three types: rapid, gradual, and symptomless.

(1) Rapid (12 cases).-Eight had a history of trauma but four seemed to have no such association. Early writers have paid special attention to the cases of sudden onset. Charcot himself described it and

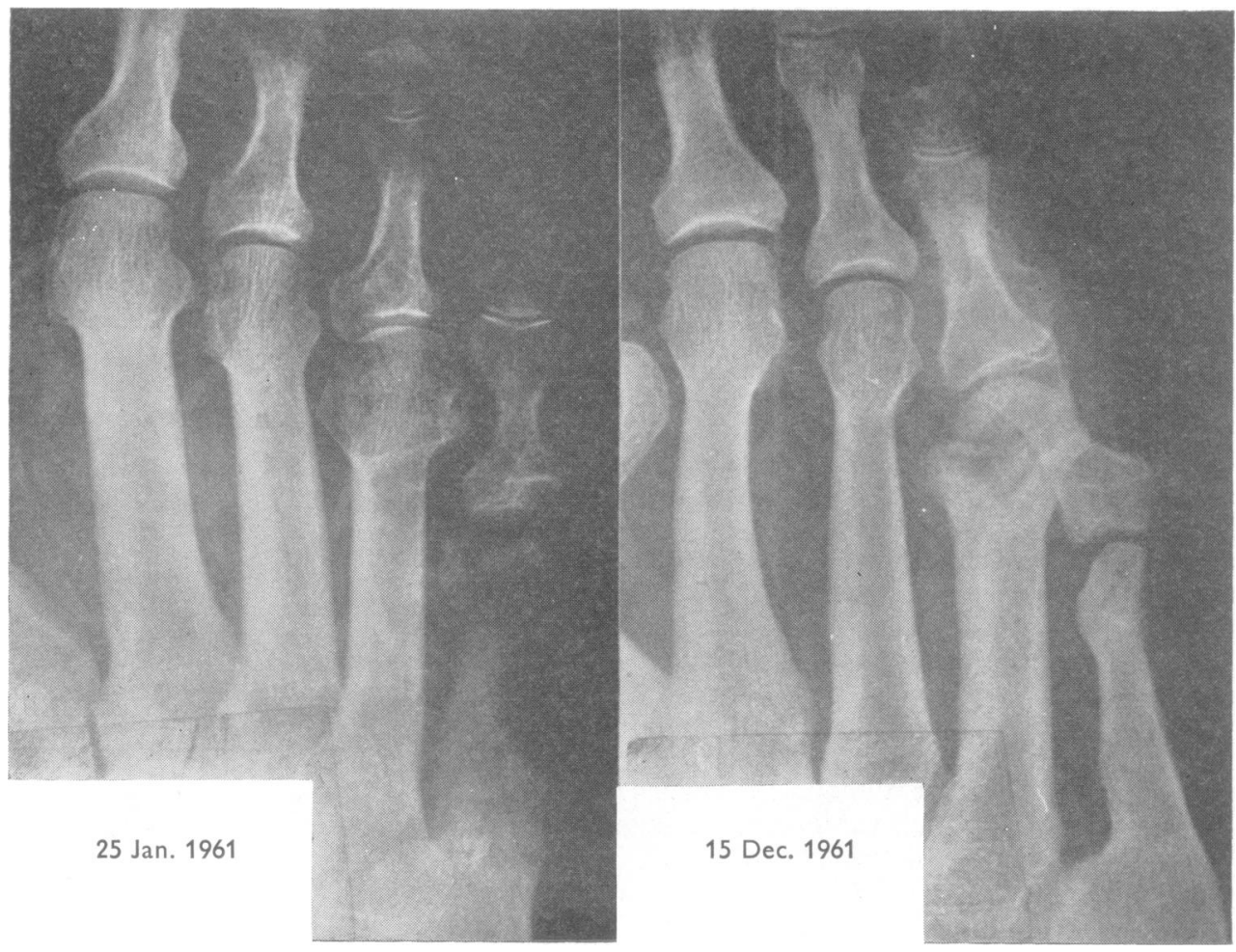

FIG. 1.-A man aged 74 years, with diabetes mellitus and slight sensory changes.

(a) 10 days after development of ulcer. The fifth metatarsal shows widespread destruction.

(b) One year later, re-formation of the bone with a short toe. 


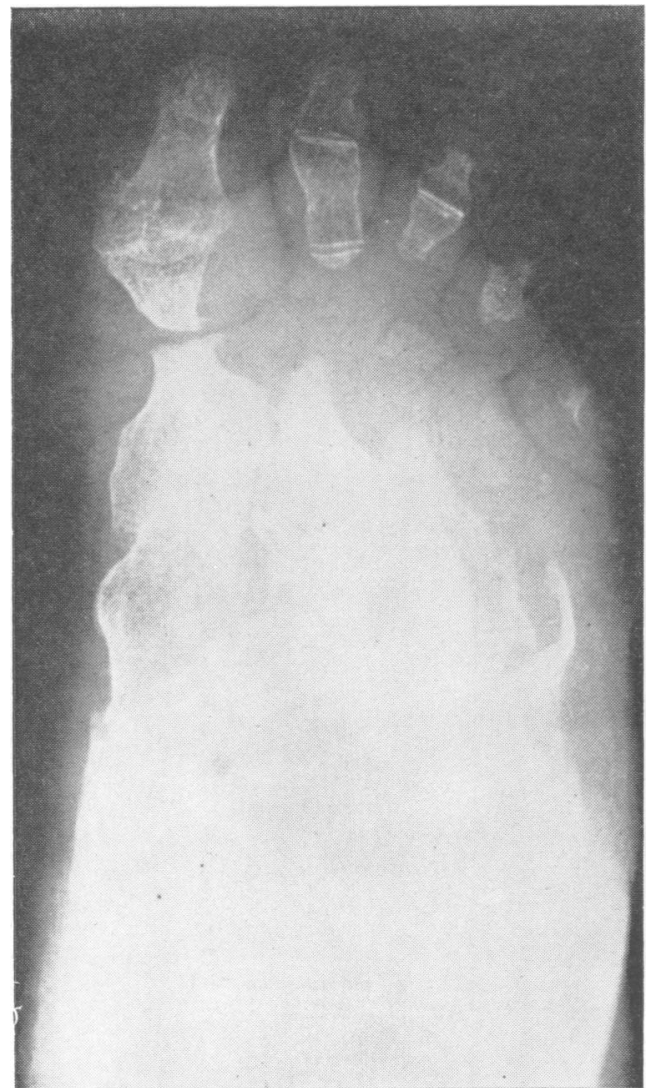

Fig. 2.-Destructive changes in foot of man aged 76 years following sciatic nerve lesion.

Key (1932) spoke of an acute onset without trauma, the swelling sometimes extending beyond the joint capsule. The swelling may be warm with tense shiny skin (Woldenberg, 1941); this state is said to settle in a week and to be followed by the more familiar chronic phase. One patient in this series showed this type of onset and the peri-articular swelling simulated thrombophlebitis and was related to a spontaneous fracture.

(2) Gradual.-In these cases there is increasing swelling and instability; pain may be felt at some stage, usually early, but may be less than would be expected from the physical signs.

(3) Asymptomatic.-In these cases the condition is found only on clinical or radiological examination. Involvement of the spine was particularly apt to be asymptomatic.

\section{Radiology}

A special feature of the series were the radiological findings, the material available often making it

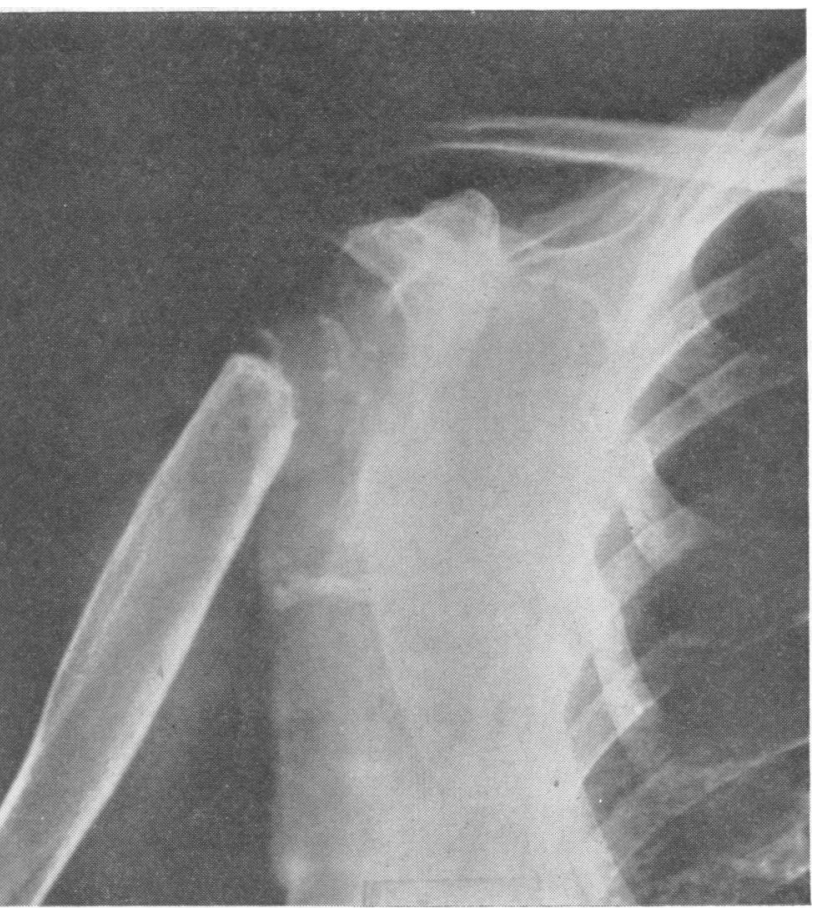

FIG. 3.-A woman aged 67 years with syringomyelia. There are atrophic changes with disappearance of the head of the humerus.

possible to follow the course of the condition. Many bizarre developments were seen, but three types of change seemed to be important: sclerotic, hypertrophic, atrophic.

(1) Sclerotic Changes.-These may be an early feature and may be the first to be seen (Katz, Rabinowitz, and Dziadiw, 1961). Fig. 4 (overleaf, p. 112) shows increased density of the bones of the right knee with loss of trabecular pattern extending up the shaft of the femur. Although the joint is affected the space is still intact; there are also cystic changes in the left patella which later progressed so that the left knee was also affected.

Fig. 5 (overleaf, p. 112) shows a later stage in the same patient; there was a fracture through the patella, followed later by some improvement with union of the fracture and restitution of the bony pattern.

Fig. 6. (overleaf, p. 113) shows a fairly typical Charcot development in the knee. There is first increased density of the bone with cyst formation, followed by a woolly or chalky appearance. Crumbling of the condyles may follow and the femur may then dislocate-usually laterally, though it may go backwards or into the tibia. 

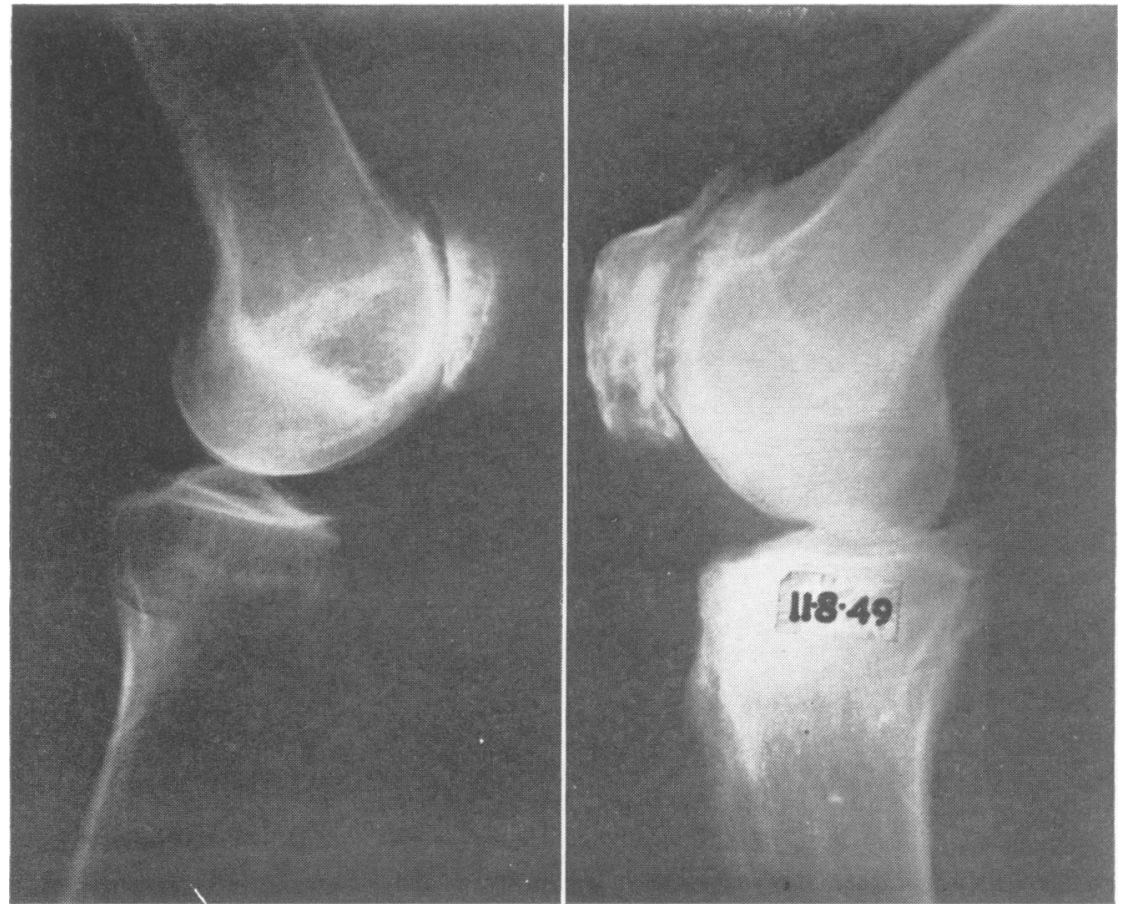

FIG. 4.-A man aged 72 years with tabes dorsalis. In 1949 there were early changes in right knee with increased density and loss of trabecular pattern. There were cystic changes in the left patella.

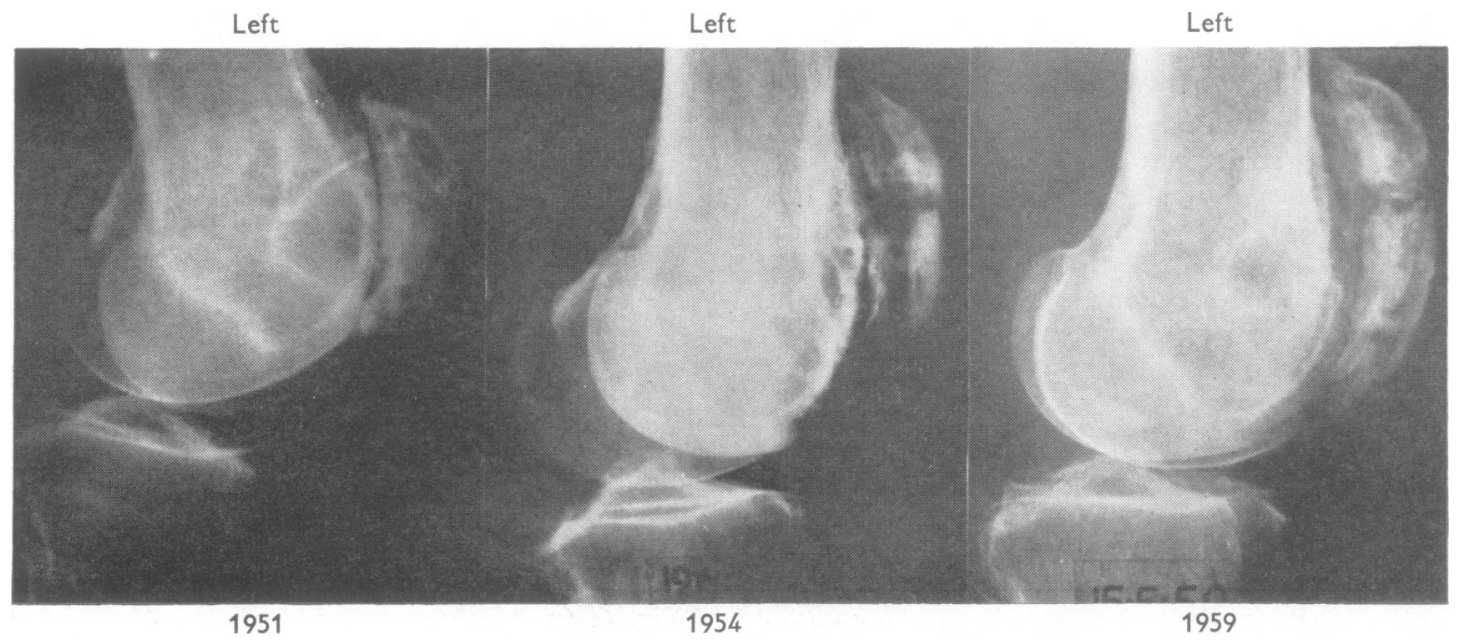

Fig. 5.-Same patient as Fig. 4. In 1951, 1954, and 1959, there were progressive changes in the left knee. The last $x$ ray shows some restitution of bone pattern and union of fracture.

These changes may occur slowly over a few years or quickly over only a few months as in Fig. 7 (opposite). Similar changes may be seen in the spine and other

joints-most commonly in the lower limbs, but also in the upper limbs. Later the sclerotic changes may disappear with restitution of the bony pattern. 


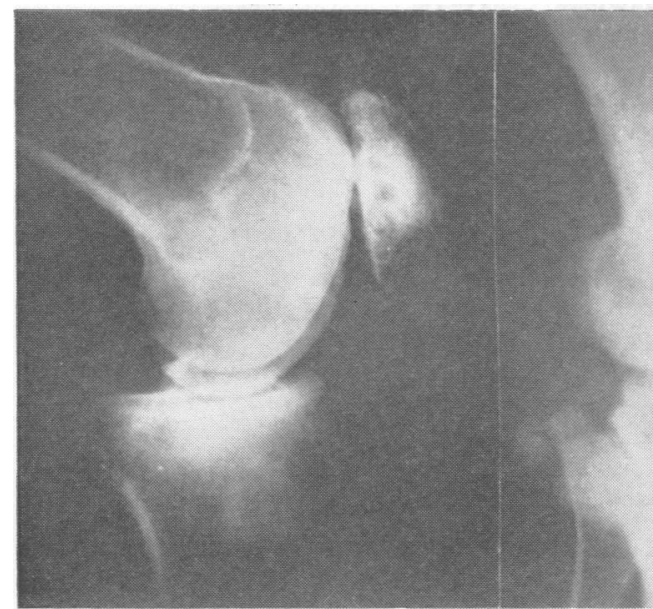

1950

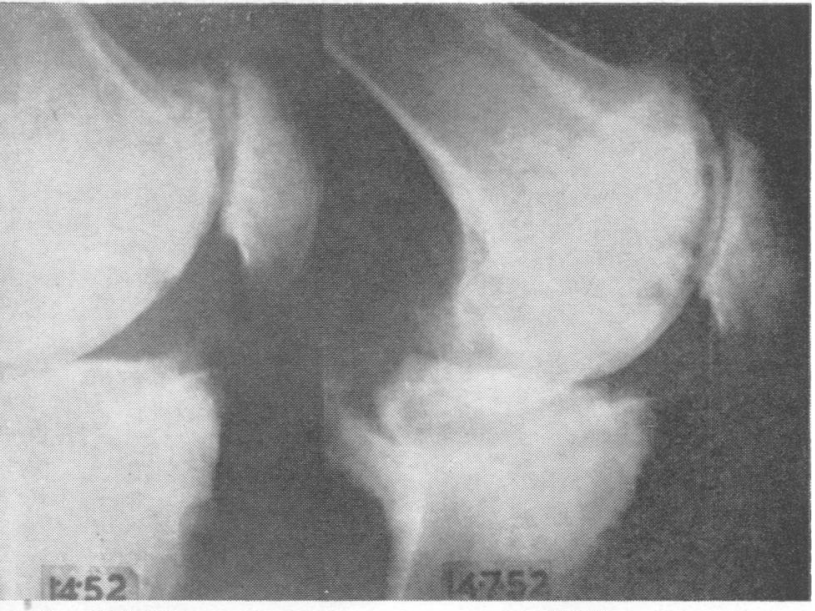

April, 1952
July, 1952

Fig. 6.-A woman aged 57 years with congenital syphilis and tabes dorsalis. The knee shows the typical development of a Charcot joint (1950-52).

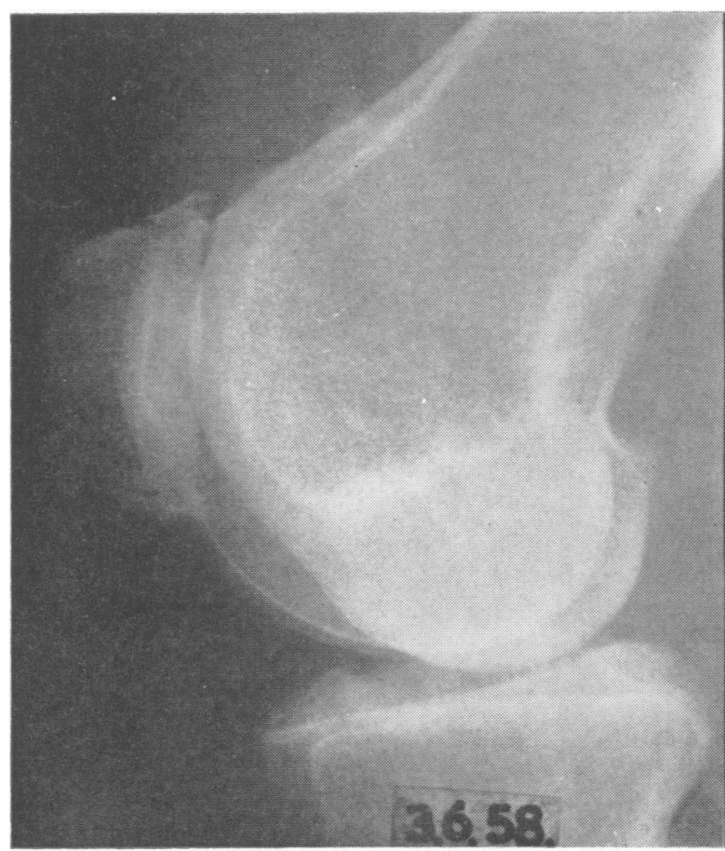

June, 1958

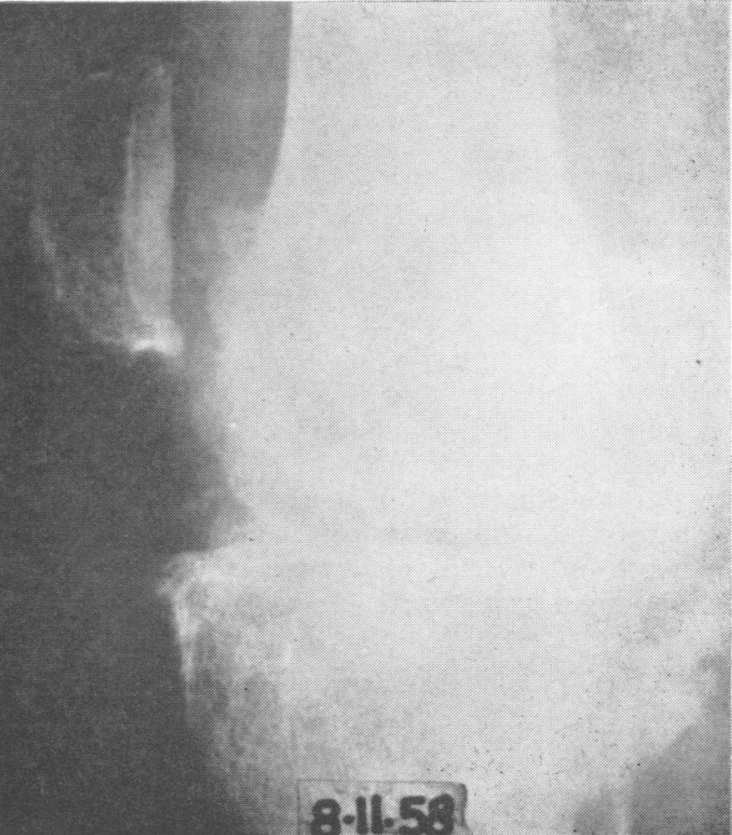

November, 1958

FIG. 7.-A woman aged 51 years with tabes dorsalis. A Charcot joint developed rapidly in the knee between June and November, 1958.

(2) Hypertrophic Changes.-These seem to represent a more stable form of the condition developing at a later stage. A man, who has been seen over the last 8 years, walks normally in a caliper and the radiological appearance has not changed in that time (Fig. 8, overleaf, p. 114).

Hypertrophic changes may lead to a uniform enlargement of the bone ends. 


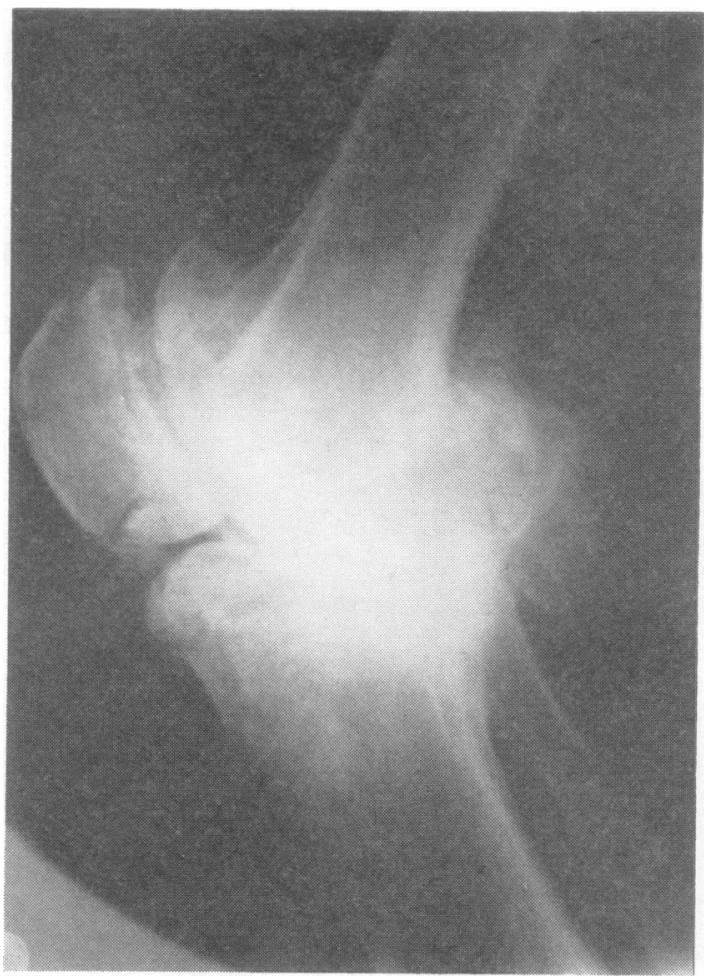

FIG. 8.-A man aged 50 years with tabes dorsalis, showing hypertrophic changes in the knee joint.

(3) Atrophic Changes.-These are seen mainly in the upper limbs in syringomyelia but also occur in the lower limbs in tabes dorsalis. Fig. 3 (above) shows such changes leading to the disappearance of the head of the humerus. It is difficult to visualize purely mechanical factors at work here-there can be hardly any contact between the upper end of the humerus and the glenoid cavity. Other radiological findings in this series included spontaneous fractures and dislocation and peri-articular calcification. Fig. 9 shows a spontaneous fracture with false joint formation.

\section{Complications}

Inflammation.-The redness and swelling occurring at the onset have already been noted. Inflammatory episodes may also occur during the course of the disease. There were eight such cases in this series: one had a transient episode of peri-articular inflammation, but in the seven others the joint itself was involved and pus was found. In three cases the pus was sterile, and in the other four Staphylococci were grown. These infections often started as a

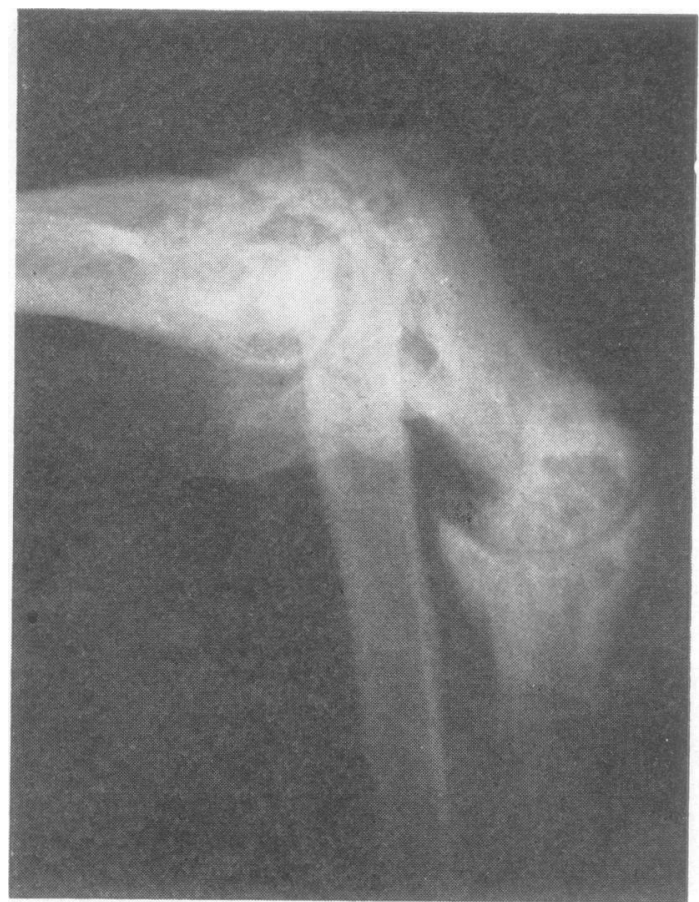

FIG. 9.-A man aged 57 years with tabes dorsalis, showing spontaneous fracture and false joint formation in the elbow.

peri-arthritic inflammation and affected a pocket of synovial membrane apparently separate from the main joint. This pocketing of synovial membrane has been described by other authors; crypts of synovia are squeezed outwards so that synovial fluid is forced out even into the subcutaneous tissue and this accounts in some cases for the peri-articular swelling and inflammation. Organisms may be found in these crypts which later invade the main joint (Shands, 1930). Peri-articular swelling may also result from a painless spontaneous fracture with the spread of oedema and haemorrhage in the tissues. This has already been noted in one patient at the onset of the disease. Infection may later involve the bone itself.

Haemorrhage into the Joint.-In one patient in this series haemorrhage into a pocket of synovial membrane produced a hard swelling apparently separate from the joint. This patient, a woman aged 52, presented with a swelling, apparently in the right breast, which was first thought to be a neoplasm, but exploration showed it to be a haematoma lying in a cavity connected to the right shoulder joint. It was found that she had syringomyelia and asymptomatic Charcot joint changes in the left shoulder and elbow. 
Pressure on Surrounding Structures.-This series included two cases of ulnar nerve compression. One patient, with spinal Charcot changes, had pressure on the lumbo-sacral plexus with paralysis of the leg. Another, with a collapsed vertebra due to tabes dorsalis, developed retention of urine which was relieved by decompression of the spinal canal.

Spontaneous Fractures and Dislocation.-These may be regarded as part of the disease process rather than as complications.

\section{Differential Diagnosis}

It is clear that Charcot joint changes may simulate most types of arthritis and may present in many different ways. They may be asymptomatic for a long time and attract attention only when complications appear. The main differential diagnoses may be summarized as follows:

Traumatic Conditions.-The occurrence of trauma at the onset has already been noted, and when a fracture or dislocation occurs the underlying condition may be missed. The Charcot joint may also present as a simple traumatic arthritis.

Acute Infective Arthritis.-This has already been discussed. There may be a true infective arthritis due to the invasion of organisms but in some cases the fluid is sterile.

Tuberculous Arthritis.-One patient in this series was accepted as a case of quiescent tuberculous arthritis of the ankle. This arose from a misleading history in the presence of a stable hypertrophic joint.

Rheumatoid Arthritis.-When pain is a symptom and the condition is polyarthritic, rheumatoid arthritis may be simulated. One patient with spindling of the fingers (reported elsewhere by Tegner, 1953) was so diagnosed for 7 years before the correct diagnosis of syringomyelia was made.

It might be expected that rheumatoid arthritis or Reiter's syndrome and tabes dorsalis could occur together in some cases, with the appearance of multiple Charcot joint changes. There was no such case in this series but one patient had both psoriasis and tabes dorsalis, in whom both conditions may have been responsible for the resultant arthropathy.

Osteo-arthritis.-The changes in the joint in the later stages resemble those of osteo-arthritis, so that the Charcot joint may be regarded as a type of osteo-arthritis, and differential diagnosis may be difficult. In old people, particularly, severe osteoarthritis may be relatively painless.

Gout may be simulated if the skin becomes red and shiny.

\section{Other Conditions of the Joints:}

(a) Synovioma.-One woman aged 56 years in this series had had the left leg amputated at another hospital for a synovioma of the knee, a diagnosis said to be supported by histology. She presented with tabes dorsalis and a Charcot joint of the right knee.

(b) Malignant Disease was also suspected in a patient with a swelling in the breast and sarcoma of the humerus was also suggested as a possible diagnosis.

(c) The peri-arthritic swelling may also simulate ThrombophleBITIS or Cellulitis.

Usually, once the possibility of a Charcot joint has been thought of, the diagnosis is easy, but that this is not always so is illustrated by the woman with psoriasis and a Charcot joint. At the age of 60 years she developed progressive painless swelling first of the left knee and then the right. The only abnormal neurological sign was an absence of deep pain. She gave no history suggestive of syphilis and a routine Wassermann test was negative. The possibility of a Charcot joint associated with psoriasis alone was considered. However, it was later found that she had had antiluetic treatment 12 years earlier and that serological tests for syphilis had been positive at that time, when she had been regarded as a case of asymptomatic neurosyphilis. Further investigation revealed that the treponemal immobilization test was still positive.

Further difficulty of diagnosis may be caused by a misleading history, sometimes given deliberately. A man aged 40 years succeeded in gaining admission to hospitals on numerous occasions by presenting with a red swollen foot with a history of recent trauma. The initial diagnosis in this case was that of an infected fracture, but he proved to have tabes dorsalis and the radiological appearance of his foot has remained unchanged for the last 5 years.

\section{Summary and Conclusions}

The exact cause of the Charcot joint must still remain in doubt. The purely mechanical theory of its causation explains most of the observed phenomena, but some features suggest the involvement of other pathological changes.

There seems to be an active phase of the disease, which may be of acute onset, in which the joint may disintegrate very rapidly. This is characterized by a change in the consistency of the bone which seems to become more friable. Radiologically the bone appears sclerotic and of a chalky consistency with cyst formation. The change may represent a response to stress, but the bone does not behave like normal bone and is more liable to crumble (WatsonJones, 1957); this suggests the involvement of some 
vasomotor mechanism as is also suggested in some cases of the atrophic type of lesion. Whether this vasomotor disturbance is nervous in origin or whether the local blood supply is impeded by local pressure is uncertain.

At a later stage the disease appears to be more stable, the joint becomes hypertrophic, the bone pattern re-forms, and the sclerotic appearance is lost. The joint then seems better able to bear weight and withstand strain.

During the course of the disease inflammatory episodes are liable to occur which with other unusual features, may cause difficulty in diagnosis. Some of the complications are described.

I wish to thank Dr W. S. Tegner and Mr A. J. King for permission to use their cases and for their advice and criticism.

\section{REFERENCES}

Antes, E. H. (1954). J. Amer. med. Ass., 156, 602.

Bailey, C. C., and Root, H. F. (1947). New Engl. J. Med., 236, 397.

Charcot, J. M. (1868). Arch. Physiol. norm. path., 1, 161. Copland, W. A. (1954). Proc. roy. Soc. Med., 47, 345.

Eloesser, L. (1917). Ann. Surg., 66, 201.

Katz, I., Rabinowitz, J. G., and Dziadiw, R. (1961). Amer. J. Roentgenol., 86, 965.

Kernwein, G., and Lyon, W. F. (1942). Ann. Surg., 115, 267.

Key, J. A. (1932). Amer. J. Syph., 16, 429.

Martin, M. M. (1954). Proc. roy. Soc. Med., 47, 139.

Parsons, H., and Norton, W. S. (1951). New Engl. J. Med., 244, 935.

Paterson, D. E. (1955). J. Fac. Radiol., 7, 35.

Shands, A. R. (1930). Arch. Surg., 20, 615.

Soto-Hall, R., and Haldeman, K. O. (1940). J. Amer. med. Ass., 114, 2076.

Tegner, W. (1953). Ann. phys. Med., 1, 182.

Vishoot, A. S. (1956). Bull. Tulane med. Fac., 15, 119.

Watson-Jones, R. (1952). "Fractures and Joint Injuries", 4th ed., vol. 1, p. 439. Livingstone, Edinburgh.

Wile, U. J., and Butler, M. G. (1930). J. Amer. med. Ass., 94, 1053.

Woldenberg, S. C. (1941). Urol. cutan. Rev., 45, 252.

Wyburn-Mason, R. (1950). "Trophic Nerves". Kimpton, London.

\section{DISCUSSION}

DR R. R. WILlcox (St. Mary's Hospital, London) said that he would be interested to know how many cases of Charcot's arthropathy were seen in V.D. clinics and how many came from medical departments. In connexion with the joints involved in the cases of syringomyelia, he wanted to know if the joints affected, other than those of the arm, were similar to those met with in tabetic cases. Finally, was there any information concerning the blood uric acid in those cases which had an acute onset?

In reply, DR STOREY said that he had no information as to the breakdown of the cases nor as to the blood uric acid levels. Most of those with acute onset seemed to be associated with trauma. In the cases of syringomyelia of the lower limb, only one joint was involved.

Mr A.J. KING (Whitechapel Clinic, London) commented on the comparatively large number of cases of syringomyelia in Dr Storey's series. It was usually thought to be a relatively uncommon disease and it used to be said that 97 per cent. of cases of Charcot joints were due to tabes dorsalis and 3 per cent. to syringomyelia. Could the method of collection have given the series a bias, or had times changed? Why was it so difficult to perform an arthrodesis successfully in cases of Charcot's arthropathy? He supposed it to be a question of blood supply, but even if the operation was done early in the course of the disease it nearly always failed. He was surprised to hear that there had been only one instance of a patient having two diseases concurrently which might result in arthropathy, namely, psoriasis and tabes dorsalis. He had a strong impression that it was a relatively common sequence of events that patients with long-standing tabes dorsalis developed osteo-arthritis, or other unrelated arthropathy, in their declining years, and that the degenerative changes of neuropathic arthritis followed. He did not think Dr Storey had mentioned the complication of root pains resulting from destruction of the vertebrae.

In reply, DR STOREY said that osteo-arthritis was a degenerative condition and, in a way, somewhat like Charcot's arthropathy-certainly, a patient who grew old and began to develop a type of osteo-arthritis would eventually develop a Charcot joint. The two processes were probably very similar and it would be very difficult to prove that the Charcot joint was secondary to an osteoarthritis. The failure of arthrodesis was certainly a fact. If two bones were opposed there must be some form of immobilization to get them to unite. If the patient did not appreciate pain that might be another hindrance apart from the failure of the blood supply. Arthrodesis did not always fail, however, and some orthopaedic surgeons considered it worth a trial. Root pains, of course, were a complication but they had not occurred in the present series. He could offer no explanation for the comparatively large number of cases of syringomyelia.

DR R. D. Catterall (General Infirmary, Leeds) asked whether Dr Storey could explain why some cases of Charcot's arthropathy experienced pain. Also, had he seen any cases of Charcot's arthropathy due to trauma? At Leeds, he had recently seen a miner who had developed classical Charcot's arthropathy of the right ankle following trauma, none of the other recognized causes of Charcot's arthropathy being present. As a flail joint had developed the foot had been amputated and histological examination revealed no specific changes. Concerning psoriatic arthritis there seemed to be two main types; the commonest were those with involvement of the terminal inter-phalangeal joints and in the others there were changes in the large joints. He was not clear whether Dr Storey had seen more than one case of Charcot's arthropathy associated with psoriasis. 
DR STOREy, in reply, said that some very odd things happened in Charcot joints and he could not explain them all. Could the patient with the Charcot changes in the right ankle have had congenital insensitivity to pain or could there have been local nerve damage as a result of the trauma? Trauma often seemed to be the exciting factor, but something else was required as well. The explanation for the occurrence of pain in Charcot's arthropathy was probably that the sensation has gone from the bone but not necessarily from the surrounding structures; a swollen joint capsule could press on surrounding structures and thus cause pain. As for Charcot changes in psoriasis; psoriasis was a complicated condition and patients might suffer from many forms of arthritis. Usually the arthritis resembled rheumatoid arthritis, but in some of the destructive forms (mutilans type) the bone was destroyed and, in some cases, this was painless.

DR A. Grimble (Guy's Hospital, London) asked Dr Storey if, in the course of cyclical changes in which the disease went through a pattern of change, he had found treatment made any difference to this. Certainly some patients seemed to improve after treatment. He would also like to know whether the main changes occurred with any definite time pattern. He had had one case in a woman in the last trimester in whom the changes developed in the course of a few days.

Dr Storey, in reply, said that his study had been largely retrospective so it was difficult to correlate the effect, if any, of antisyphilitic treatment. There was no apparent pattern-in some cases changes developed very rapidly and in others they appeared slowly over a period of years.

\section{Les articulations de Charcot}

\section{RÉSUMÉ}

La cause exacte des articulations dîtes de Charcot n'est pas encore connue. Une origine mécanique explique la plupart de nos observations, mais quelques caractères suggèrent la présence d'autres changements pathologiques.

Au cours d'une phase active de la maladie dont le développement peut être soudain, l'articulation peut s'affaisser rapidement. L'os devient friable, et le radiographe montre une formation sclérotique de craie avec des kystes. Ce changement peut être dû au stress, mais la structure osseuse est anormale et poudreuse (WatsonJones, 1957), chose qui indique que le mécanisme vasomoteur est affecté, comme on le voit dans les lésions atrophiques. On ne sait pas si cette condition vasomotrice est d'origine nerveuse ou si la circulation du sang est interrompue.

Dans la phase secondaire la maladie est stabilisée, l'articulation devient hypertrophique, l'os se reforme, et la sclérose disparaît. En même temps l'articulation peut mieux supporter le poids du corps.

$\mathrm{Au}$ cours de la maladie les épisodes inflammatoires ainsi que d'autres caractères bizarres rendent le diagnostic bien difficile. L'auteur décrit de telles complications. 